\title{
REFERENCIA AL ARTÍCULO "TRATAMIENTO QUIRÚRGICO DEL COMPLEJO EXTROFIA-EPISPADIAS. REVISIÓN Y CONCEPTOS ACTUALES"
}

\author{
A. ORSOLA DE LOS SANTOS
}

Servicio de Urología. Clinica Plató. Barcelona.

Actas Urol Esp. 28 (2): 157-158, 2004

\section{Señor Director:}

El motivo de esta carta es el de aportar algunos comentarios en referencia al artículo "Tratamiento quirúrgico del complejo extrofiaepispadias. Revisión y conceptos actuales", publicado en la revista Actas Urológicas Españolas 27 (6): 450-457, 2003 ${ }^{1}$. En el mencionado artículo se realiza la presentación de un caso de cierre neonatal completo (total neonatal reconstruction) del complejo extrofia-epispadias, conjuntamente con la revisión de la literatura de la evolución de las distintas técnicas quirúrgicas para la reparación de esta malformación.

El artículo presenta la incorporación de la técnica antirreflujo descrita por Gil-Vernet ${ }^{2}$ como "un nuevo paso a la técnica descrita por Mitchell (...) esta combinación supone una novedad no descrita previamente (...)". Guisiera señalar que la innovación de asociar el avance ureteral de GilVernet al cierre de la vejiga, uretra y pene en un tiempo (cierre neonatal completo) fue publicada con anterioridad en el BJU Int ${ }^{3}$, tras ser presentada el año 2002 en el prestigioso congreso anual de la European Society for Pediatric Urology (ESPU). Los autores, encabezados por De Castro (con una amplia experiencia en extrofia vesical ${ }^{4}$ ), realizaron el procedimiento de Gil-Vernet con el objetivo de obtener una cierta ventaja al añadir esta técnica como mecanismo antirreflujo. Tres pacientes de su serie fueron sometidos a este método de avance ureteral al tiempo del cierre de la extrofia, siguiendo la técnica de cierre neonatal completo. Ninguno de ellos presentó reflujo vesicoureteral en el seguimiento.
Por otro lado, apuntar que se echa de menos en el artículo de De la Peña et al. ${ }^{1}$ una lectura crítica de las posibles limitaciones que la incorporación de este paso quirúrgico podría suponer. Sin duda la propuesta de añadir el avance ureteral o trigonoplastia de Gil-Vernet ${ }^{2}$ al cierre completo de la extrofia resulta atractiva. Sin embargo, el texto no hace mención de las diferencias que la técnica antirreflujo de Gil-Vernet presenta en los casos de extrofia vesical respecto a los de reflujo vesicouretral convencional. Entre ellas, la diastasis pubiana, el defecto en el refuerzo posterior del suelo vesical, la existencia de un cuello vesical incompetente que debe corregirse y posiblemente la distinta anatomía del trayecto intramural ureteral son algunos de los puntos que pudieran haberse tenido en cuenta en el momento de autoevaluar la eficacia potencial de este mecanismo antirreflujo en estos pacientes. De todos modos, como bien apuntan De Castro et al., "se requiere más experiencia y un seguimiento más largo para saber si esta técnica será realmente de interés"3.

Finalmente, el artículo de De la Peña et al. ${ }^{1}$ menciona que Mitchell "comunicó en 1996 los primeros resultados de una nueva técnica quirúrgica basada en la corrección simultánea de la extrofia vesical y el epispadias ${ }^{5}$ ". El citado artículo, de Mitchell y Bägli ${ }^{5}$, en realidad sólo describía la reparación del epispadias empleando la movilización completa de la placa uretral y ambos cuerpos cavernosos. Aunque en dicha publicación uno de los niños fue también sometido al cierre de la extrofia, no fue hasta 1999 que Grady y Mitchell presentaron formalmente (en dos 
publicaciones) la primera serie de pacientes sometidos al cierre vesical-uretral completo en un tiempo, describiendo el llamado total neonatal reconstruction ${ }^{6,7}$. Creo que la autoría de Grady en el increíble avance que supuso esta técnica en el manejo de esta rara malformación vesical, pélvica y abdominal, debería serle reconocida.

Respetuosamente,

\section{REFERENCIAS}

1. DE LA PEÑA E, HIDALGO J, CAFFARATTI J, GARAT JM, VILLAVICENCIO H.: Tratamiento quirúrgico del complejo extrofia-epispadias. Revisión y conceptos actuales. Actas Urol Esp 2003; 27: 450-457.

2. GIL-VERNET J.: A new technique for surgical correction of vesicoureteral reflux. J Urol 1984; 131: 456458.

3. DE CASTRO R, EL-TIRAIFI A, AL ABD AL AALY M.: Is VUR preventable in bladder extrophy during one-stage complete repair? BJU Int 2002; 89 (Suppl. 2): 64.
4. DE CASTRO R, PAVANELlO P, DOMINI R.: Indications for bladder augmentation in the extrophy-epispadias complex. Br J Urol 1994; 73: 303-307.

5. MITCHELL ME, BAGLI DJ.: Complete penile disassembly for epispadias repair: the Mitchell technique. J Urol 1996; 155: 300-304.

6. GRADY RW, MITCHELL ME.: Complete primary repair of extrophy. $J$ Urol 1999; 162: 1415-1420.

7. GRADY RW, CARR MC, MITCHELL ME.: Complete primary closure if bladder extrophy. Epispadias and bladder extrophy repair. Urol Clin North Am 1999; 26: 95-109, viii.

Dra. Anna Orsola de los Santos

Servicio de Urología

Clínica Plató. Fundació Privada

C/ Plató, 21

08006 Barcelona

(Trabajo recibido el 17 septiembre de 2003) 